\title{
The effect of two finishing and polishing systems on the surface roughness of two composite resins
}

Accepted: $23 / 9 / 2012$

\begin{tabular}{ccc}
\hline Media A. Saeed $*$ & Intesar S. Toma $*$ & Razawa K. Saeed $*$ \\
\hline Abstract &
\end{tabular}

Background and objective: The purpose of this study was to evaluate the effect of two finishing and polishing systems on the surface roughness of two different types of composite resins.

Methods: Fourty samples of $6 \mathrm{~mm}$ in diameter and $2 \mathrm{~mm}$ in depth were prepared, 2 types of composite resins were used (nanocomposite and hybrid composite resin). Twenty samples of each type of material were prepared and divided into two main groups and then each main group subdivided randomly into two subgroups of 10 samples each. Ten samples of each material were submitted to finishing by finishing disc. While the other 10 samples of each material were submitted to finishing by finishing bur. Both finishing systems were used with a slow-speed hand piece in a dry field and with a light intermittent pressure for about 15 seconds for each disc and bur. After storage of the samples for 48 hours; the analysis of the surface roughness was carried out, three readings were made on each surface using a stylus tip, and the extension of each reading was $2 \mathrm{~mm}$ stroke.

Results: There was non significant difference between the groups except there was a significant difference between the two finishing systems when used with hybrid composite.

Conclusion: Finishing discs gave best results on nano composite and hybrid composite when compared with finishing diamond bur, with highly significant effect on nano composite.

Keywords: Nano composite, Hybrid composite, Finishing bur, Finishing disc.

\section{Introduction}

Regardless of the cavity class and location, a smooth surface finish is clinically important, as it determines the esthetics and longevity of composite resin restorations ${ }^{1}$. It has been reported that achieving a restorations surface smoothness is vital for its success ${ }^{2}$. Finishing and polishing of composite resin restorations are essential steps in restorative dentistry ${ }^{3}$. The esthetics and life span of tooth-colored restorative materials are dependent on the quality of the surface finish ${ }^{4}$. Polishing is the process carried out after the finishing procedure to remove minute scratches from the surface of a restoration and obtained a smooth, light reflective luster ${ }^{5}$. In general, a variety of instruments are commonly used for finishing and polishing tooth -coloured restorative materials, finishing is performed with diamonds of varying abrasive particle sizes and tungsten carbide finishing burs. For years, a set of flexible discs coated with aluminum oxide and other rotary instruments were used for polishing resin restorations ${ }^{6}$. The final polishing result depends on the filler size, shape, and loading in the resin composite 7 . The various types of filler now in use affect the handling characteristics and also the physical properties of the composite resins. Along the years, composites containing macro-, micro- and nano particles have been proposed. Nowadays, only few macrofile composites are still in use, because of their inadequate surface condition ${ }^{8}$. In recent years, manufacturers have improved resin based composites by reducing particle size, increasing filler quantity, improving adhesion between the

* Department of Conservative Dentistry, College of Dentistry, Hawler Medical University, Erbil, Iraq. 
filler and the organic matrix, and using lowmolecular- weight monomers to improve handling and polymerization ${ }^{9}$. Due to the differences in filler size and type, alternative polishing concepts were applied in this study. This study was undertaken to determine the effectiveness of two polishing systems on two types of composite resin aesthetic materials by evaluating surface roughness using a profilometer.

\section{Methods}

40 samples were prepared by pouring a plastic tube $2.5 \mathrm{~cm}$ in diameter and $2 \mathrm{~cm}$ in height with cold cure acrylic resin. The cylindrical cavities of $6 \mathrm{~mm}$ in diameter and $2 \mathrm{~mm}$ in depth were cut at the center of cold cure acrylic resin blocks, by placing a metal mold on the acrylic resin at the dough stage of setting of acrylic resin. Two types of composite resins were used, 20 samples of each type of material were prepared. Specimens were randomly divided into two groups and each group then subdivided into two other groups of 10 samples each. Composite resin was inserted into the mold, a celluloid strip and a glass slab were placed over the composite resin under the load of $200 \mathrm{gm}^{10}$ to remove excess material. Then after removal of the glass slab, the sample will be light cured by halogen light curing device for 40 second according to manufacturer instructions between all steps of the procedure. The samples were stored in distilled water in an incubator at $37 C^{\circ} 10,11$. Ten Samples of each material were submitted to finishing and polishing with aluminum oxide finishing disc (Rihani int, USA), on a low speed hand piece without water-cooling. The following discs were used in sequence: coarse (white), medium (blue), fine (yellow) and superfine (pink) each for $15 \mathrm{sec}$. . The other 10 samples were polished with finishing bur. Then after storage for 48 hours; the analysis of the surface roughness was carried out all specimens were individually positioned in a surface recorder profilometer to verify the roughness $(\mathrm{Ra})$ values of the material surface. Three readings were made on each surface using a stylus tip, and the extension of each reading was $2 \mathrm{~mm}$ stroke.

\section{Results}

By using paired t- test, there was non significant difference between all the groups at $p>0.05$, except there was significant differences between the two finishing systems when used with hybrid composite at $p<0.05$, Table 1, 2 and Figure 1. Generally groups of nano composite gave best results than groups of hybrid composite, especially when nano composite group finished by finishing disc.

Table 1: The descriptive statistic of roughness reading

\begin{tabular}{llllll} 
composite & Finishing system & No. of samples & Mean of scores & SD & $\begin{array}{c}\text { Std. Error } \\
\text { Mean }\end{array}$ \\
\hline Nano & Finishing bur & 10 & 0.312 & \pm 0.065 & 0.020 \\
Nano & Finishing disc & 10 & 0.225 & \pm 0.054 & 0.017 \\
Hybrid & Finishing bur & 10 & 0.444 & \pm 0.198 & 0.062 \\
Hybrid & Finishing disc & 10 & 0.260 & \pm 0.087 & 0.027
\end{tabular}


Table 2: t-test for difference between the groups

\begin{tabular}{llcccc} 
Groups & techniques differences & df & t-statistic & P-value & Sign. \\
\hline Nano & Finishing disc - Finishing bur & 18 & -3.276 & 0.004 & HS \\
Hybrid & Finishing disc - Finishing bur & 18 & -2.687 & 0.015 & S \\
Finishing bur & Nano - Hybrid & 18 & -1.990 & 0.062 & NS \\
Finishing disc & Nano- Hybrid & 18 & -1.077 & 0.296 & NS
\end{tabular}

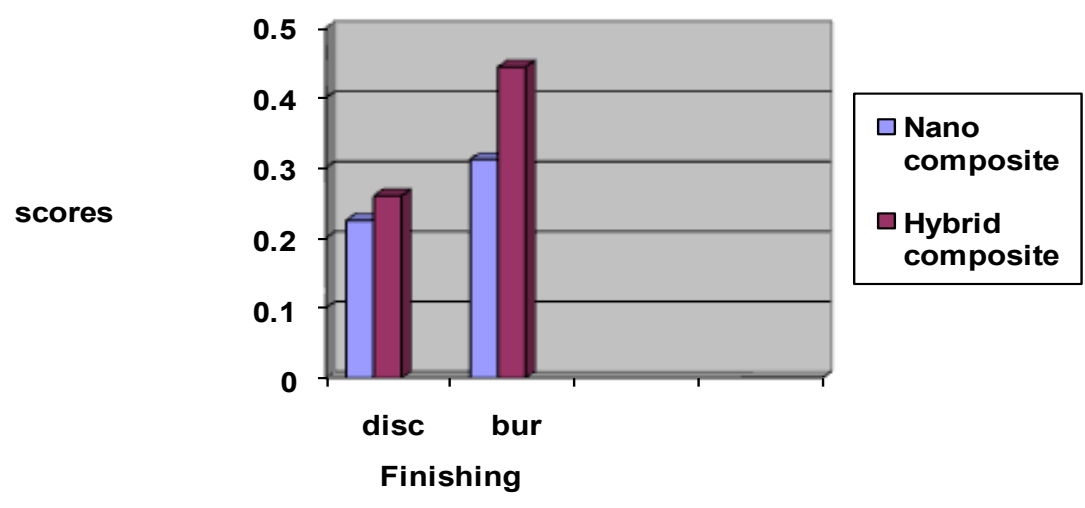

Figure 1: Bar chart showing the roughness difference between the groups

\section{Discussion}

Proper finishing and polishing of dental restorations are important aspects of clinical restorative procedures that enhance the longevity of restored teeth ${ }^{12-15}$, establish a functional occlusal relationship and a contour physiologically in harmony with supporting tissues. In addition, proper contour and high gloss give the restoration the appearance of natural tooth structure ${ }^{16}$. Residual surface roughness associated with improper finishing and polishing of dental restorations can result in clinical problems for both patient and the clinician. These problems include excessive plaque accumulation, gingival irritation, increased surface staining, and poor or less than optimal esthetic of the restored teeth ${ }^{14,17}$. In dentistry, surface roughness measurements are usually carried out with the help of a profilometer ${ }^{18,19}$. In the current study, the profilometer was used to determine surface roughness. Arithmetical surface roughness average (Ra) is the most commonly used parameter in the assessment of surface roughness ${ }^{20-22}$. The inherent surface roughness of a restoration must be equal to or lower than the surface roughness of enamel on enamel- to - enamel occlusal contact $(\mathrm{Ra}=0.64)^{6}$. It has been suggested that the degree of polymerization of resin composites affects the hardness of the resin matrix. The greater the conversion rate of carbon double bonds, the higher the hardness value ${ }^{23,24}$. In the current study, in order to obtain adequate polymerization, all samples were polymerized according to the manufacturers' instructions using a halogen curing light with 
constant time. Smoother composite surfaces are obtained when the material was cured against a polyester matrix ${ }^{25-30}$. Even if care is taken in the placement of the matrix, removal of excess material and re-contouring of restorations are frequently necessary. However, these procedures significantly increase surface roughness. Thus, a large number of polishing techniques is available for composites ${ }^{31}$. Composite surface roughness is basically dictated by the size, hardness, and amount of filler which influences the mechanical properties of the resin composites. It is also influenced by the flexibility of the finishing material, the hardness of the abrasive and the grit size ${ }^{16,18,32,33-34}$. The hypothesis of this study was that the polishing technique and filler content of the composite resin would affect surface roughness. The results of this study support the research hypothesis. The results revealed that Composan bio-esthetic nano composite finished with aluminium oxide finishing disc showed lower surface roughness average value $(\mathrm{Ra}=0.225 \mathrm{Mm})$, due to their small filler particle size and their filler arrangement. The average size of nano composite filler particle is $25 \mathrm{~nm}$ and nano aggregates of approximately $75 \mathrm{~nm}{ }^{35}$. While Composan ceram hybrid composite finished with diamond bur showed the higher surface roughness average value $(\mathrm{Ra}=0.44 \mathrm{Mm})$, due to their harder and larger filler particle size 0.6 to $1 \mathrm{Mm}^{35}$. In addition, it has been suggested that filler size and load have the potential to influence the surface characteristics of a resin composite ${ }^{36}$. Filler particles should be situated as close as possible in order to protect the resin matrix from abrasives. Reduced inter particle spacing in resin composites is achieved by decreasing the size and increasing the volume fraction of fillers ${ }^{37}$. Harder filler particles are left protruding from the surface during polishing as the softer resin matrix is preferentially removed. Resin composites with larger filler particles are expected to have higher $\mathrm{Ra}$ value after polishing. Therefore, nano composite can be finished to a smoother surface than the hybrid composite evaluated in this study. The present results corroborate with those found by Vera et al ${ }^{38}$, Gulati and Hegde ${ }^{5}$ and Vera et al. , ${ }^{39}$ who demonstrated that nano composites finished with aluminum oxide disc showed the lower surface roughness and this fact is related to the small fillers size, highly loaded and more homogenously distributed in matrix. In addition to the capacity of discs to reduce fillers and matrix evenly. Also this study corroborated with Duygu et al ${ }^{37}$. Who demonstrated that hybrid composite showed high roughness average value $\mathrm{Ra}$, possibly due to the size of the filler particles that were exposed after polishing or dislodge. The capacity of discs impregnated with aluminum oxide particles produces smooth surfaces is related to their ability of equally removing particles and organic matrix. Previous studies have reported that aluminum oxide disks provided the smoothest surface on resin restoratives which is related to their tendency to abrade filler particles and resin matrix equally without dislodgment the filler particles and gouging into the material ${ }^{6,40}$. Overall, the diamond burs were less effective than aluminum oxide finishing discs for finishing the composites. These findings are in accordance with Halim et al. , ${ }^{41}$ and Andre et al ${ }^{42}$, who reported higher values of surface roughness for polishing with diamond burs. As expected, the diamond finishing bur produced rough surfaces on both composites. The rougher surfaces produced by the diamond burs might be related to their grain sizes and scratches might be created on the surfaces of composites. Andre et al ${ }^{42}$, reported that when diamond bur were applied, scratches and some pitting were observed on the surface of the composite, which may have been due to plucking of the filler particles during polishing. The pits were proportional to filler sizes. Also in the present study, Composan bio-esthetic nano composite showed a highly significant differences when finished with aluminum oxide finishing discs, while Composan ceram hybrid composite 
showed a significant differences using the same finishing discs system when compared with a diamond finishing bur. This means aluminum oxide finishing discs produced smoothest surfaces for the two materials when compared with finishing bur. Furthermore, the finishing disc has more efficiently finished the composite surfaces for the same reasons as previously mentioned. Authors also underlined that the disc system is able to remove the surface scratches created by the finishing bur ${ }^{6,43}$. Kreistine et al. ${ }^{40}$, reported that each resin behaves according to polishing system used. Tamayo et al. ${ }^{36}$, reported that the effect of polishing systems on surface finish was material dependent. While, Vera et al. ${ }^{38}$ reported that the final surface texture was material and technique dependent. In the present study the final polish obtained on a composite restoration would be determined by two factors; composition of composite with the relation to matrix and filler particles and the type of polishing system used.

\section{Conclusion}

Nano composite gave best results than hybrid composite, especially when nano composite finished by finishing disc.

\section{References}

1.Yap AU, Yap SH, Teo CK, Ng JJ. Finishing/ polishing of composite and compomer restoratives: effectiveness of one-step systems. Oper Dent 2004;29:275-9.

2.Ana LBM, Patricia PNS, Patricia ADS, Juliana ADB. Surface roughness and hardness of a composite resin: Influence of finishing and polishing and immersion methods. Materials Research 2010: 13(3): 409-415.

3.Roeder LB, Powers JM. Surface roughness of resin composite prepared by single-use and multiuse diamonds. Am J Dent 2004;17:109-12.

4.Dunkin RT, Chambers DW. Gingival response to class $\mathrm{V}$ composite resin restorations. J Am Dent Assoc 1983;106:482-4.

5.Gulati GS, Hegde RS. Comparative evaluation of two polishing systems on the surface texture of an aesthetic material (nano-composite): A profilometric study. Peoples Journal of Scientific Research 2010; 3(2): 17-20.

6.Cigdem C, Gul O. Effect of finishing and polishing procedures on surface roughness of tooth colored materials. Quintessence International 2009; 40 (9): 783- 789.

7.Tatsuo E, Werner J, Masafumi K, Andreas U, Masashi K. Surface texture and roughness of polished nanofill and nanohybrid resin composites. Dental Materials Journal 2010; 29(2): 213-223.

8.Iulia RG, Malina N, Georgescu A, Gianina I. On the surface condition of composite resins obtained by various finishing techniques. Journal of Romanian Medical Dentistry 2010; 14(4): 265-268.

9.Rustu G, Feridun H, Akin C, Ozden O, Ali K. Surface roughness of new microhybrid resin-based composites. JADA 2005; 136:1107-1112.

10.Cunha L G, Alonso R C, Santos P H, Sinhoreti M A. Comparative study of the surface roughness of ormocer-based and 'conventional composites. J Appl Oral Sci 2003; 11(4): 348-53.

11.Garcia F. Wang L. D’Alpino P.de Souza J. Araújo P. de Lia Mondelli R. Evaluation of the roughness and mass loss of the flowable composites after simulated tooth brushing abrasion. Braz Oral Res 2004; 18(2): 156-61.

12.Berastegui E, Canalda C, Brau E, Miquel C. Surface roughness of finished composite resins. J Prosthetic Dent 1992; 68: 742-749.

13.Jefferies SR, Barkmeier WW, Gwinnett AJ. Three composite finishing systems: a multisite in vitro evaluation. J Esthetic Dent 1992; 4:181-185.

14.Jefferies SR. the art and since of abrasive finishing and polishing in restorative dentistry. Dent Clin N Am 1998; 42:613-627.

15.Tate WH, DeSchepper EJ, Cody T. Quantitative analysis of six composite polishing techniques on a hybrid composite material. J Esthet Dent 1992; 4:30-32.

16.Turkun LS, Turkun M. The effect of one- step polishing system on the surface roughness of three esthetic resin composite materials. Oper Dent 2004; 29:203-211.

17. Shaintani H, Satou J, Satou N, Hayashihara , Inoue $\mathrm{T}$. Effects of various finishing methods on staining and accumulation of Streptococcus mutans HS-6 on composite resins. Dent Mater 1985; $1: 225-227$

18.Baseren $M$. Surface roughness of nanofill and nanohybrid composite resin and ormocer-based tooth-colored restorative materials after several finishing and polishing procedures. Journal of Biomaterials Applications 2004; 19(2) 121-134.

19.Scurria MS, Powers JM. Surface roughness of two polished ceramic materials. Journal of Prosthetic Dentistry 1994; 71(2) 174-177.

20.Setcos JC, Tarim B, Suzuki S Surface finish produced on resin composites by new polishing systems. Quintessence International 1999; 30(3) 169-173.

21.Pedrini D, Candido MS, Rodriques AL. Analysis of surface roughness of glass-ionomer cements and compomer. Journal of Oral Rehabilitation 2003; 30(7) 714-719.

22.Wilder AD Jr, Swift EJ Jr, May KN Jr, Thompson 
JY, McDougal RA. Effect of finishing technique on the microleakage and surface texture of resinmodified glass ionomer restorative materials. Journal of Dentistry 2000; 28(5) 367- 373.

23.Asmussen E. Restorative resins: Hardness and strength vs. quantity of remaining double bonds. Scandinavian Journal of Dental Research 1982: 90(6) 484-489.

24.Ferracane JL, Greener EH . The effect of resin formulation on the degree of conversion and mechanical properties of dental restorative resins. Journal of Biomedical Materials Research. 1986; 20(1) 121-131.

25.Chung $\mathrm{KH}$. Effects of finishing and polishing procedures on the surface texture of resin composites. Dent Mater 1994;10:325-30.

26. Hondrum SO, Fernandez R Jr. Contouring, finishing, and polishing class $\mathrm{V}$ restorative materials. Oper Dent 1997;22:30-6.

27. Zgünaltay G, Yazici AR, Grücü J. Effect of finishing and polishing procedures on the surface roughness of new tooth-colored restoratives. J Oral Rehabil. 2003;30:218-24.

28.Roeder LB, Tate WH, Powers JM. Effect of finishing and polishing procedures on the surface roughness of packable composites. Oper Dent 2000;25:534-43.

29. Tate $W H$, Powers JM. Surface roughness of composites and hybrid ionomers. Oper Dent 1996;21:53-8.

30. Yap AU, Lye KW, Sau CW. Surface characteristics of tooth-colored restoratives polished utilizing different polishing systems. Oper Dent 1997;22:260-5.

31. Jung M. Finishing and polishing of a hybrid composite and a heat pressed glass ceramic. Oper Dent 2002;27:175-83.

32. Barghi N, Lind SD. A guide to polishing direct composite resin restorations. Compend Contin Educ Dent 2000; 21(2):138-144.

33. Reis AF, Giannini M, Lovadino JR. The effect of six polishing systems on the surface roughness of two packable resin- based composite. Am J Dent 2002; 15:193-197.

34.Choi MS, Lee YK, Lim BS, Rhee SH, Yang HC. Changes in surface characteristics of dental resin composites after polishing. Mater Sci Mater Med 2005; 16(4): 347-353.

35.Adela HG, Miguel AM, Jose CV, Amaya BE, Pablo FG. Composite resins. A review of the materials and clinical indications. Clinical Dentistry 2006; 11:215-220.

36 . Tamayo W, Masahi M, Toshiki T, Hiroyasu K, Akitomo Rm Susumu A. Influence f polishing duration on surface roughness of resin composites. Journal of Oral Science 2005; 1:21-25.

37. Duygu S, Sinasi S, Safak k, Cagri U, Tolga K. The effect of polishing techniques on the surface roughness and color change of composite resin. J Prosthet Dent 2006; 96:33-40.

38.Vera LS, Regina MP, Fabiana SN, Flavia PSN,
Mario ACS, Wagner B. Effect of the polishing procedures on color stability and surface roughness of composite resins. International Scholarly Research Network ISRN Dentistry 2011; 10: 1-6.

39. Vera LS, Regina MP, Fabiana SN, Danielle L, Julio KU, Lornco CS. Effect of finishing and polishing techniques on the surface roughness of a nano particle composite resin. Braz J Oral Sci 2011; 10(2): 105-108.

40. Kristine GBA, Karoline GBA, Igor SM, Jose FC, Claudia MCA. Effect of different polishing systems on the surface roughness of microhybrid composites. J Appl Oral Sci 2009; 17(1): 21-26.

41. Halim NF, Maria TF, Haline DN, Fernanda PM. Surface roughness of composite resins after finishing and polishing. Braz Dent J 2003 14(1): 1 6.

42. Andre FR, Marcelo G, Jose RL, Carlos TD. The effect of six polishing systems on the surface roughness of two packable resin- based composites. Research Article 2002; 15: 193-197.

43. Ozgunaltay G, Yazici AR, Gorucu J. Effect of finishing and polishing and polishing procedures on the surface roughness of new tooth-coloured restoratives. J Oral Rehabil 2003; 28:218-224. 